\title{
Public Health in South East Asia: Current realities and future directions
}

\author{
Dr. Md. Anwarul Azim Majumder \\ Editor, South East Asia Journal of Public Health,E-mail: editor@phfbd.org
}

While there has been an explosion of scientific and technological discoveries that help diagnose, prevent, and treat diseases, the countries of the South East Asia region have failed to fully reap the benefits of these breakthroughs for many reasons. There is a lack of modern facilities, effective regulations, systematic planning and universal coverage of public health services in most of the South East Asian countries. The main threats to public health today in the region are more complex, associated with a combination of regional as well as global factors, which include demographic shifting, epidemiological trends, climate change, increased international mobility, information and communication revolution, war and terrorism, privatization and deregulation of health care, and increasing levels of health inequality both within and between countries. The region is home to approximately $25 \%$ of the world's population and bears almost $30 \%$ of the global disease burden including a large proportion of maternal and child mortality and morbidity, infectious diseases such as malaria, tuberculosis, HIV, as well as an epidemic of noncommunicable diseases such as cardiovascular diseases, cancer, diabetes, chronic respiratory diseases and other conditions like mental illness, injuries and disabilities. Despite the magnitude of these interrelated challenges, the countries in the region spend on average $3.8 \%$ of their gross domestic products on health, compared to a global average of $8.5 \%$, which is the lowest among WHO (World Health Organization) regions (in contrast, the highest level is found in the region of the Americas at $12.6 \%$ ). ${ }^{1}$ The per capita health expenditure is US\$47 in the South-East Asia region in comparison to US\$2902 per capita in the region of the Americas (African region: US\$83; Eastern Mediterranean region: US\$153; Western Pacific region: US\$447; global average: US\$854). ${ }^{1}$ The health systems in this region are often focused on curative care, which is underfunded, undermanaged, and further challenged by a lack of availability of competent and skill mix public health workforce. In many countries, public health systems are either not functioning efficiently or are in a state of decline due to a lack of resources, political commitment and effective leadership and management.

Public health is the science and art of preventing diseases, prolonging life and promoting health through the organized efforts and informed choices of society, organizations (public or private), communities, and individuals. ${ }^{2}$ Another important concept related to public health is health promotion. According to the WHO, 'health promotion is the process of enabling people to increase control over, and to improve their health.' This reflects the notion that, health is a basic human right and endorses a range of ways of improving the quality of life of populations, communities and individuals through healthy public health policies. Since 1970s, the WHO has sought to shift the emphasis of health policy towards disease prevention and health promotion, mainly through its 'Health for All by the Year 2000 ' principle which was further developed at international conferences at Alma Ata (1978), Ottawa (1986), Adelaide (1988), Sundsvall (1991), Jakarta (1997), Mexico City (2000), Bangkok (2005), and Nairobi (2009). The 'Health for All' strategy was subsequently revised for the twentyfirst century, and sustainable development and environmental health issues are now at the top of the agenda. There is a greater emphasis on promoting equity in health and addressing the socioeconomic determinants and renewed emphasis on public engagement in the development of health promotion initiatives. South East Asian countries and organizations concerned with health need to be more proactive in promoting policies and strategies to combat specific threats in relation to public health and health promotion. Most of the countries in the region suffer a chronic shortage of health personnel in public health specialties, especially in rural areas. Moreover, medical students and other health professionals are less interested in pursuing a career in those specialties and to work in rural areas (please see the article on career choices $^{3}$ in this issue). Public health education and training need to be strengthened in order to develop a leadership cadre of public health professionals, and to attract and retain a public health workforce to improve the quality of healthcare available to the public. Existing public health curricula and training programs in health profession institutes should be reviewed to document relevant competencies, and performance indicators must be used to produce a need-based public health workforce. ${ }^{4,5}$ Countries should properly address their health workforce needs, recruitment, retention and training, if they are to come close to reaching the Millennium Development Goals (MDGs) for health. The core areas for strengthening should include: the promotion of evidence-based public health policies; the

Correspondence: Dr. Md. Anwarul Azim Majumder, Lecturer, Department of Clinical Sciences, School of Medical Sciences, University of Bradford, Bradford BD7 1DP, UK. E-mail: a.a.majumder@bradford.ac.uk

South East Asia Journal of Public Health 2011:1:1. @ 2011 Majumder, publisher and licensee Public Health Foundation, Bangladesh. This is an Open Access article which permits unrestricted non-commercial use, provided the original work is properly cited. 
development of institutional capabilities for closing the gap between knowledge and practice; the development of appropriate human resources at all levels; the promotion of healthy lifestyles with the involvement of civil society; the strengthening of public health regulation and health financing; community based public health research; and the ability to solve complex societal problems through multidisciplinary intervention. ${ }^{5}$

The Public Health Foundation, Bangladesh (PHFBD) (http://phfbd.org/) was established in 2010 with an aim to achieve a healthy society by promoting an evidence-based public health system working in partnership with the government, private investors and other stakeholders through research, health promotion, training and technical assistance. It is an independent, autonomous, non-political organization and lead by a group of well reputed, devoted, and dedicated physicians, researchers, scientists, public health specialists, dentists and others professionals. The PHFBD has also decided to launch an open access, peer reviewed and refereed international journal: The South East Asia Journal of Public Health.

With this first issue, we are very pleased to announce the launch of the South East Asia Journal of Public Health. The aim of the journal is to act as a 'publication hub' and publish papers covering a whole spectrum of issues covering the theory and practice of public health, medicine and healthcare. The journal is published using an open access publication model, meaning that all interested readers are able to freely access the journal online without the need for a subscription. The journal has a distinguished editorial board with extensive academic qualifications and experiences and has a broad international coverage.

This inaugural issue owes much to many people. Thanks are due first to the Executive Board of the PHFBD, where the idea of publishing a journal originated, particularly the Chairman (Prof. Muzaherul Huq) and the CEO (Prof. Mahmuda Chowdhury), for their unfailing support, advice and encouragement. It is also our great pleasure to welcome the members of the International Advisory Board and Editorial Board of South East Asia Journal of Public Health. We are sure that their international reputation and great expertise in this field will have a significant contribution in shaping up the journal and making it a prestigious international journal. Most of all, thanks are due to the Associate Editors (Dr. Sayeeda Rahman, Dr. Tabassum Ferdous Khan, Dr. Shegufta Mohammad Cherry and Mr. Amir Mohammad Sayem) and Desktop Publisher (Mr. Nizam Khan), who have so generously given their time and expertise to make this project happen.

Finally, the Executive Editor wishes to thank the authors who submitted papers to the first issue of the journal. We are grateful that they responded to our invitation. Many thanks to the reviewers of the papers submitted to the journal. We rely on their expertise for reviewing and accepting papers for the journal. Therefore their contribution to the journal is invaluable and we are grateful to them for giving up their own free time to review papers for the journal. We hope they will continue to help us in the future. A special thanks to Md. Sayed Shehran Azim for final proof reading of all the articles, checking and correcting the English language, grammar and style, and also finding some errors which even the authors and editors overlooked.

We hope that this new journal will serve the public health community well and will be the main 'hub' of presenting ideas and research work in this area. Any suggestion on how to improve our activity in order to deliver a better journal to the authors, readers and subscribers of this journal will always be much appreciated. I would like to encourage all of you to contribute your scientific works for the publication in the South East Asia Journal of Public Health.

Biomedical and public health research in Asia have not received the same level of attention as they do in the developed world. ${ }^{6-9}$ There is a noticeable underrepresentation of research publications from Asia in the topranked journals. ${ }^{6-9}$ Steps should be taken to enhance collaboration and share national experiences, support cross border training, develop research networks, capacity and infrastructure, publication of journals (including ejournals), political leadership and commitment, strategic setting of priorities, and use of research to formulate public health policy and practices. ${ }^{6,9} \mathrm{I}$ hope the PHFBD and South East Asia Journal of Public Health will take a leadership role in promoting research, education and practice in the arena of public health, which ultimately facilitate the meeting of the challenges facing healthcare and medical education in the South East Asia region.

\section{References}

1. WHO. World Health Statistics 2011. Geneva: World Health Organization, 2011.

2. Walness, D. Securing good health for the whole population. London: HM Treasury, 2004.

3. Ahmed SMM, Majumdar MAA, Karim R, Rahman S, Rahman N. Career choices in preventive and social medicine and other non-clinical specialities among medical students: Bangladesh perspective. South Asia J Public Health 2011;1:12.

4. WHO. Developing Health Promotion Competencies and Standards for Countries in WHO South-East Asia Region. Report of a Meeting of experts WHO/SEARO, New Delhi, 18-20 June 2008. New Delhi: World Health Organization, Regional Office for South-East Asia, 2010.

5. WHO. South-East Asia Public Health Initiative. Report of the First Meeting of the Strategic Advisory Group, SEARO, New Delhi, 1-2 November 2004. New Delhi: World Health Organization, Regional Office for SouthEast Asia, 2005. 
6. Majumder MAA. Issues and priorities of medical education research in Asia. Ann Acad Med Singapore 2004;33:257-63.

7. Sadana R, D'Souza C, Hyder AA, Chowdhury AM. Importance of health research in South Asia. BMJ 2004;328:826-30.

8. Rahman M. Biomedical publications in south Asian countries. Indian J Public Health 2003;47:72-4.
9. Majumder MAA, Shaban SF, Rahman S, Rahman N, Ahmed SMM, Abdulrahman KB, Islam Z. Biomedical publications in the SAARC countries: 1985-2009. Submitted in Journal of College of Physicians and Surgeons, Pakistan. (Unpublished) 